ARTIG0

Recebido em: $14 / 05 / 2014$

Aceito em: 02/08/2014

\title{
Avaliação de redes multidisciplinares com a ferramenta scriptlattes: os casos da nanotecnologia, da dengue e de um programa de pós-graduação Stricto Sensu em Administração \\ Multidisciplinary networks evaluation with Scriptlattes tool: the cases of nanotechnology, dengue and a post graduate in management course
}

\author{
Renato Ribeiro Nogueira FERRAZ1 \\ LUC QUONIAM $^{2}$
}

Lillian Maria Araújo de Rezende ALVARES ${ }^{3}$

\section{RESUMO}

O Scriptlattes é uma ferramenta computacional que extrai informações acadêmicas e profissionais de pesquisadores cadastrados no CNPq, criando relatórios de produção, gráficos de colaboração e internacionalização da pesquisa, além de mapas geográficos de investigação. Neste trabalho utilizou-se o Scriptlattes para avaliar as redes multidisciplinares de colaboração em dois assuntos prioritários para o Brasil: a dengue e a nanotecnologia, além de avaliar as redes de colaboração entre os professores de um Programa de Pós-graduação Stricto Sensu em Administração. A disponibilização dos resultados, além facilitar a visualização de maneira organizada de uma série de informações anteriormente fragmentadas e disponíveis apenas nos currículos individuais dos pesquisadores cadastrados na Plataforma Lattes, contribui para divulgação ao grande público dos resultados das pesquisas realizadas entre as redes de colaboração em pesquisa.

PALAVRAS-CHAVE: Redes. Colaboração. Scriptlattes. Nanotecnologia. Dengue.

\begin{abstract}
The Scriptlattes is a computational tool that extracts academic and professional information from researchers registered at $\mathrm{CNPq}$, creating production reports, graphics of research internationalization, collaboration, and geographical research maps. In this work we used the Scriptlattes to assess multidisciplinary collaboration networks in two Brazilian priority issues: dengue and nanotechnology, as well as to evaluate the networks of collaboration among Postgraduate Administration Program teachers. The availability of results, plus easy viewing in an organized way a series of fragmented information previously available only in the individual curricula of researchers registered in the Lattes Platform, contributes to the general public dissemination of the research results conducted between collaboration networks.
\end{abstract}

KEYWORDS: Networks. Collaboration. Scriptlattes. Nanotechnology. Dengue.

v. 19, n. $40,2014$. p. $67-98$

ISSN 1518-2924

\footnotetext{
1 Universidade Nove de Julho - renato@nefro.epm.br

2 Universidade Nove de Julho - mail@quoniam.info

3 Universidade de Brasília - lillian@alvarestech.com
} 


\section{INTRODUÇão}

\subsection{Sociedade em rede}

O início do século XXI alavancou uma nova era da sociedade: a sociedade em rede. A ciência das redes, por sua própria natureza, já surgiu com características transdisciplinares, buscando respostas para os inúmeros desafios do novo milênio (CAVALCANTE, 2011). Indivíduos de todos os cantos do mundo vivenciam diariamente os avanços tecnológicos dos produtos e serviços, percebendo facilmente tais mudanças sociais multidimensionais, mesmo sem a necessidade de se preocupar diretamente com elas. A sociedade não segue mais uma disciplina apenas normativa sobre o que deve ou não deve ser feito, baseada em instruções vindas de autoridades, repletas de vazios e narcisismos intelectuais, especialmente porque essa sociedade encontra-se interligada por uma enorme rede de informações (CASTELLS; CARDOSO, 2006).

Os avanços tecnológicos são necessários, embora ainda não suficientes para suportar as novas formas de organização em rede, especialmente aquelas relacionadas ao trabalho, que se destacam entre as inúmeras modalidades de redes digitais disponíveis. A riqueza, o poder e a geração de conhecimento dependem fortemente da capacidade de organização em rede de uma sociedade. A sociedade em rede é a estrutura social resultante da interação entre os novos paradigmas tecnológicos e a organização social em geral (CASTELLS; CARDOSO, 2006). Dessa forma, a atual sociedade encontra-se imensamente dependente de inúmeras redes de relacionamento. Segundo Cavalcante (2011), "a transmissão de doenças está diretamente relacionada à constituição da rede de conexão entre as pessoas", "os terroristas formam redes entre si com o objetivo de organizar um determinado atentado" e "autores de um determinado ramo da ciência citam uns aos outros formando uma rede de citações". 


\subsection{Os pesquisadores e as redes sociais}

Os relacionamentos entre as pessoas têm sido há tempos modelados pelas redes. Analisando tais relacionamentos torna-se importante identificar, por exemplo, quais são os indivíduos mais importantes para que a rede permaneça conectada, que distância separa cada um dos componentes da rede, quais são os componentes da rede que estão conectados ao maior número de indivíduos e, essencialmente, quem está conectado a quem (CAVALCANTE, 2011).

A Ciência da Informação estuda as inúmeras relações existentes em uma rede (CAVALCANTE, 2011). Com relação às redes de colaboração entre pesquisadores, a produção científica, que corresponde ao produto da comunicação científica, figura entre os principais temas estudados por este ramo da Ciência da Informação. A análise da produção científica de um país, sobre um assunto, ou de um grupo de pesquisadores, permite acompanhar a evolução do desenvolvimento de qualquer área relacionada ao conhecimento da humanidade. Para isso, existem algumas ferramentas que possibilitam medir esse conhecimento, tais como a Informetria, a Cientometria e a Bibliometria. Essas ferramentas possibilitam realizar um mapeamento evolutivo da ciência, conhecendo as redes estabelecidas pelos pesquisadores de um determinado assunto, identificando os principais grupos responsáveis pelas publicações em uma área, bem como permitindo escalonar os grupos de pesquisadores de acordo com seu nível de contribuição científica em determinado tema (MACHADO, 2007).

Já na década de 1960 do século XX, estudando uma rede de citações entre artigos científicos, Solla Price (1965) observou que o número de vezes que um artigo é citado, e o número de artigos citados por um artigo, apresentam distribuição exponencial. Dessa forma, têm-se os trabalhos de Solla Price como os pioneiros na discussão sobre a vantagem cumulativa com relação às citações de uma obra, observadas especialmente quando os pesquisadores se organizam em redes (CAVALCANTE, 2011). 
A utilização de modelagens matemáticas e a apresentação dos resultados de suas análises na forma de gráficos constituem-se em importantes ferramentas para a análise das redes entre pesquisadores. 0 desenvolvimento das referidas teorias, assim como de ferramentas que busquem automatizar a análise das redes, tem se mostrado uma área de pesquisa bastante promissora dentro da Ciência da Informação, buscando estabelecer condições que aproximem os pesquisadores de áreas distintas através do compartilhamento de seus métodos de coleta e de análise de dados, que podem ser utilizados em diferentes ramos da pesquisa (MATHEUS; SILVA, 2006). De um modo geral, as redes de pesquisa podem ser estudadas com diferentes intuitos, especialmente voltados à otimização de algoritmos (nos estudos de Matemática Aplicada), aos mercados e economias em rede (nos estudos de Economia), aos movimentos sociais (no caso da Sociologia), aos estudos relacionados à disseminação de vírus de computador (na área de Tecnologia da Informação), e aos estudos do padrão de distribuição de doenças (que são os estudos epidemiológicos de interesse na área de Saúde Pública) (WATTS, 1999), dentre outros.

Em um estudo sobre a análise das redes sociais como metodologia de apoio para a discussão da interdisciplinaridade em Ciência da Informação, realizada tomando como base os professores pertencentes a um Programa de Pós-Graduação na mesma área, Matheus; Parreiras e Parreiras (2006), destacam que a interdisciplinaridade verificada entre as redes permite definir abordagens distintas para um mesmo problema de pesquisa, já que as diferentes realidades vivenciadas em cada área se aproximam na busca da solução para um determinado problema, que é avaliado sob diferentes óticas e com variados instrumentais. 
Os autores destacam ainda que a análise dessas redes de colaboração permite a identificação de inúmeros "colégios invisíveis", que correspondem aos pesquisadores que realizam trabalhos em conjunto, mas que não se encontram próximos fisicamente pois, na maioria dos casos, não trabalham na mesma instituição, possuem idiomas e nacionalidades distintos, e são unidos tão somente pelo objeto de pesquisa que por eles é compartilhado. Resultados semelhantes aos apresentados por Matheus; Parreiras e Parreiras (2006), com enfoque especial na transparência que deve existir quando se trata da divulgação dos resultados das pesquisas científicas e dos próprios colégios invisíveis, foram recentemente demonstrados tomando como base os professores pertencentes a um Programa de Pós-Graduação Stricto Sensu em Administração, assim como os pesquisadores cadastrados na Plataforma Lattes e que dedicam suas pesquisas a dois assuntos prioritários para o Brasil na atualidade: a nanotecnologia (QUONIAM; FERRAZ, 2014) e a dengue.

\subsection{A Plataforma Lattes}

A Plataforma Lattes foi desenvolvida pelo CNPq (Conselho Nacional de Desenvolvimento Científico e Tecnológico) para unificar o cadastro dos pesquisadores atuantes no Brasil (GUEDES, 2001). A partir de sua criação, passou-se a contar com uma base curricular única, que em 2012 possuía aproximadamente dois milhões de currículos (ALVES; YANASSE; SOMA, 2012). Os dados da Plataforma Lattes são utilizados pelos órgãos competentes para qualificar os pesquisadores e conceder fomento em pesquisa, visando o desenvolvimento científico e tecnológico nacional. Apesar da existência de plataformas curriculares semelhantes em alguns países latino-americanos e também em Portugal, somente no Brasil as informações dos currículos presentes na Plataforma Lattes estão vinculadas não só aos critérios para concessão de fomento em pesquisa, mas também aos mecanismos de avaliação da qualidade do ensino superior brasileiro, especialmente dos cursos de PósGraduação Stricto Sensu, que são monitorados pela Coordenação de Aperfeiçoamento de Pessoal de Ensino Superior (CAPES).

Além de permitir a visualização individualizada dos currículos dos pesquisadores que atuam no Brasil, a Plataforma Lattes constitui-se em uma 
valorosa fonte de dados para avaliação de redes sociais estabelecidas entre esses pesquisadores (BALANCIERI et al., 2005). A importância do estabelecimento de redes de pesquisa é essencial para o progresso da ciência e desenvolvimento do conhecimento científico. Ainda, a Plataforma Lattes permite o acesso a informações que não podem ser encontradas nas bases referenciais, e sim apenas nos currículos dos pesquisadores, especialmente aquelas que permitem traçar um panorama dos futuros resultados das pesquisas científicas em desenvolvimento, como os projetos submetidos e as orientações em andamento. No entanto, é importante ressaltar que o CNPq não disponibiliza uma forma adequada para que se tenha acesso às informações de um conjunto de currículos cadastrados na Plataforma Lattes, o que obriga os pesquisadores interessados em conduzir estudos envolvendo essencialmente as redes de colaboração entre os pesquisadores sobre determinado assunto, ou então envolvendo um grupo de pesquisadores, por exemplo, pertencentes a um Programa de Pós-Graduação específico, dependam da solicitação e liberação de dados pelo próprio CNPq (LEITE; MUGNAINI; LETA, 2011; MUGNAINI; LEITE; LETA, 2012).

\subsection{A ferramenta computacional Scriptlattes}

o Scriptlattes constitui-se em uma ferramenta computacional capaz de baixar os currículos Lattes de um grupo específico de pesquisadores cadastrados na Plataforma Lattes e extrair desses currículos as informações acadêmicas e profissionais que se queira analisar. A ferramenta exclui produções redundantes e cria relatórios específicos para agrupar as diferentes modalidades de produção, gera diversos gráficos de colaboração, de internacionalização da pesquisa, e mapas geográficos de investigação (MENACHALCO; JUNIOR; MARCONDES, 2009).

Diversos módulos computacionais sequenciais são executados pelo Scriptlattes com base em listas contendo os nomes e os ID Lattes dos pesquisadores dos quais se deseja extrair a produção. O ID Lattes corresponde a um registro único constituído por um código de 16 algarismos que identifica o pesquisador na Plataforma Lattes. Tais listas podem ser montadas 
manualmente (por exemplo, quando se deseja extrair a produção de um grupo de professores de um determinado departamento acadêmico), ou de maneira automatizada (tomando como base uma procura por palavras-chave que devem ser realizadas diretamente no sistema de busca da Plataforma Lattes e no Diretório de Grupos de Pesquisa do CNPq). Montadas as listas, o módulo inicial do Scriptlattes extrai da Plataforma Lattes os currículos que se deseja analisar e, logo a seguir, realiza um tratamento prévio dos dados constantes nesses currículos, especialmente excluindo informações redundantes. Em uma próxima etapa, a ferramenta cria gráficos que demonstram as redes de colaboração existentes entre os pesquisadores listados, gera relatórios de produção bibliográfica, técnica e artística, além de um relatório de orientações acadêmicas. Após a finalização dos mecanismos de extração e tratamento dos currículos, o Scriptlattes cria uma série de pastas contendo arquivos no formato html (linguagem de marcação de hipertexto utilizada para produzir páginas na $w e b)$ que contém as listas de produções dos pesquisadores listados. Essas pastas devem ser enviadas e armazenadas em um servidor de internet, que fornecerá um endereço eletrônico para que se tenha acesso às páginas geradas a partir dos referidos arquivos, bastando para tal digitar o endereço eletrônico fornecido pelo provedor de internet na janela de qualquer navegador.

O Scriptlattes tem sido utilizado para realizar análise de informações com base na extração de dados curriculares da Plataforma Lattes (MENA-CHALCO; JUNIOR; MARCONDES, 2009; QUONIAM; FERRAZ, 2014), fornecendo resultados de grande valia, especialmente no tangente à análise de competências em pesquisa, à transparência de informações acadêmicas, e à investigação das redes multidisciplinares de colaboração entre diversos autores.

\subsection{Dengue: uma das principais doenças negligenciadas no Brasil e no mundo}

As doenças de elevada prevalência, especialmente nas populações mais pobres, são definidas como doenças negligenciadas (DN). Tais mazelas costumam acometer principalmente crianças, contribuindo sobremaneira para o aumento da mortalidade infantil (FERREIRA et al., 2009), embora também 
contribuam consideravelmente para a redução da capacidade produtiva dos adultos (ROCHA, 2012), e para a manutenção da precariedade e inequidade social (HOTEZ, 2007; WERNECK; HASSELMANN; GOUVÊA, 2011). O termo "negligenciadas" decorre do fato de que tais doenças não se constituem no foco das pesquisas científicas, em especial pelo desinteresse das indústrias farmacêuticas por doenças pouco lucrativas. Dessa forma, os métodos de prevenção, diagnóstico e tratamento são antigos, muitas vezes obsoletos e ineficazes (WERNECK; HASSELMANN; GOUVÊA, 2011; YAMEY, 2002). A estimativa atual é que existam cerca de um bilhão de indivíduos acometidos por alguma DN em todo o mundo.

A dengue é uma das DN mais relevantes, especialmente porque atinge tanto áreas rurais quanto urbanas e, diferente de outras DN, atinge pessoas de todas as classes sociais, já que o seu transmissor, o mosquito Aedes aegypti, desenvolve-se em qualquer ambiente que possua acúmulo de água limpa e parada. Não existem vacinas disponíveis para a prevenção contra a infecção pelo vírus da dengue e pouco se pode fazer com relação ao seu tratamento. A doença, de prevalência pandêmica no Brasil, pode apresentar formas graves que podem levar o doente à morte (WILDER-SMITH; GUBLER, 2008). Afeta aproximadamente 3,6 bilhões de pessoas em mais de 125 países, predominando em regiões de clima tropical e subtropical (WHO, 1997; WILDER-SMITH; GUBLER, 2008). Sua incidência aumentou consideravelmente nas últimas décadas, o que coloca em risco metade da população mundial (WILDER-SMITH; GUBLER, 2008). Anualmente, cerca de meio milhão de hospitalizações são realizadas em decorrência da infecção pela dengue, e algo em torno de 50-100 milhões de novos casos surgem a cada ano (WILDER-SMITH; GUBLER, 2008).

As pesquisas em dengue realizadas no Brasil não são suficientes para acompanhar o crescente aumento no número de casos da doença. Talvez esse quadro decorra da reduzida concessão de fomento para as pesquisas em DN, ou então de uma falta de entrosamento entre os pesquisadores em dengue no Brasil, que talvez não mantenham relações suficientes de maneira que suas descobertas possam contribuir umas com as outras para a evolução no conhecimento dos diversos aspectos ligados a dengue. Existe uma vasta 
produção científica em dengue, que pode ser visualizada com base em pesquisas bibliográficas, mas não se conhece ao certo quais são os projetos de pesquisa vigentes, quais são as dissertações de mestrado e doutorado atualmente orientadas sobre o assunto, tão pouco se conhecem as redes multidisciplinares de relacionamento entre os pesquisadores em dengue no país.

\subsection{Nanotecnologia: um assunto prioritário para o Brasil}

A nanotecnologia pode ser compreendida como o entendimento, o controle, o processamento e a caracterização da matéria em dimensões típicas de 0,1 a 100 nanômetros (nm), e constitui-se em uma área cada vez mais relevante no contexto de ciência e engenharia, com um grande potencial para promoção de inovações de impacto para a sociedade (KOSTOFF; KOYTCHEFF; LAU, 2007).

Os estudos em nanotecnologia têm se mostrado uma área de pesquisa de interesse prioritário para o Brasil, visto que a indústria nacional tem sido obrigada a competir internacionalmente com os produtos fabricados em países de avançada tecnologia. O Brasil somente obterá sucesso competitivo em nanotecnologia se atingir a capacidade de gerar produtos e processos inovadores e que possam ser comparados àqueles produzidos pela indústria internacional. Dessa forma, o conteúdo tecnológico dos produtos oferecidos pela indústria brasileira terá de avançar substancialmente nos próximos anos, o que obriga o Brasil a realizar investimentos de peso nas pesquisas envolvendo nanotecnologia.

0 mapeamento da atividade científica em nanotecnologia é relevante para a compreensão do passado, presente e futuro das agendas de pesquisa. Assim como no caso das doenças negligenciadas, uma considerável produção científica sobre o tema nanotecnologia pode ser encontrada nas bases bibliográficas nacionais e internacionais. Todavia, torna-se muito difícil traçar o perfil dos resultados das pesquisas em nanotecnologia vigentes no país, visto que tais informações, também relacionadas às teses e dissertações em orientação, bem como aos projetos de pesquisa vigentes, não se encontram disponíveis nas bases bibliográficas e sim apenas isoladamente nos currículos 
dos pesquisadores. Ainda, não se dispõem de um panorama relacionado às relações entre os pesquisadores em nanotecnologia no país. Na atualidade, torna-se complicado identificar as redes multidisciplinares de pesquisa em nanotecnologia, especialmente com o intuito de integração das pesquisas em andamento, já que não existem ferramentas comprovadamente eficazes para tal.

\subsection{Avaliação dos Programas de Pós-graduação Stricto Sensu brasileiros}

Nas últimas décadas tem sido notada uma considerável evolução nos mecanismos de avaliação dos cursos superiores no Brasil, com especial destaque para a avaliação dos cursos de Pós-Graduação Stricto Sensu. Segundo Maccari (2008), essa evolução é essencial para o desenvolvimento científico e tecnológico no Brasil, já que contribui para a manutenção da qualidade na formação de recursos humanos especializados.

As avaliações de curso são importantes ao ponto em que permitem que as instituições de ensino superior conheçam suas próprias limitações e criem programas de reestruturação e adequação dos processos voltados à formação acadêmica (WALTER et al., 2013). Já em 2006, o INEP - Instituto Nacional de Estudos e Pesquisas Educacionais, definiu que a avaliação do ensino superior é importante, pois estimula mudanças no comportamento das universidades, especialmente em seus modelos de gestão educacional. Dessa forma, entende-se que a avaliação é o mais importante mecanismo utilizado para estabelecer um padrão mínimo de desenvolvimento das instituições e da qualidade do ensino superior.

Com a atual tendência da transparência em pesquisa, e perante a necessidade de se estabelecer e tornar públicas as redes multidisciplinares de colaboração entre pesquisadores, no caso de um programa de Stricto Sensu, com o especial intuito de alavancar a produção científica e contribuir para o sucesso na avaliação do Programa no momento da prestação de contas aos órgãos de avaliação da qualidade do ensino superior, especialmente a CAPES, surge a necessidade da criação de ferramentas computacionais capazes de extrair, compilar e disponibilizar de maneira organizada as produções científicas dos pesquisadores pertencentes a um departamento de Pós-Graduação. 


\section{OBJETIVO}

Demonstrar a eficácia da ferramenta computacional Scriptlattes na avaliação das redes multidisciplinares de colaboração entre os pesquisadores em nanotecnologia e entre os pesquisadores em dengue em âmbito nacional, assim como na avaliação da rede de colaboração entre os professores pertencentes a um Programa de Pós-Graduação Stricto Sensu em Administração.

\section{METODOLOGIA}

\subsection{Descrição da ferramenta}

O trabalho original de Mena-Chalco e César Júnior (2009), descreve detalhadamente o processo de tratamento de currículos extraídos da Plataforma Lattes, bem como a montagem das páginas $h t m l$ que disponibilizarão na web os resultados desse tratamento. Neste trabalho apresentamos apenas uma descrição simplificada do referido processo computacional, com base em listas montadas automaticamente para análise das competências atuantes no Brasil nos assuntos dengue e nanotecnologia, além de suas redes de colaboração, e em listas produzidas manualmente para avaliação das produções científicas e redes de colaboração existentes entre os professores pertencentes a um Programa de Pós-Graduação Stricto Sensu em Administração.

A Plataforma Lattes não permite que quaisquer dados sejam coletados diretamente de sua base. Todavia, a utilização de procedimentos computacionais possibilita recuperar as informações que se deseja analisar diretamente dos currículos depositados na Plataforma. Cada pesquisador registrado na Plataforma Lattes possui um ID Lattes, que permite o acesso a uma página na web onde o currículo do referido pesquisador fica hospedado. Para que se possa extrair dados da Plataforma Lattes, torna-se então necessário criar arquivos no formato texto contendo listas com os ID Lattes dos pesquisadores que se deseja avaliar a produção científica e as redes de colaboração. Neste trabalho, para a análise das produções científicas e redes de colaboração dos professores pertencentes ao Programa de Pós-Graduação 
Stricto Sensu que foi utilizado como exemplo, tais foram montadas manualmente, bastando para tal realizar uma procura pelos nomes dos pesquisadores na plataforma Lattes, anotando o número dos ID. Para a análise das competências nos assuntos "dengue" e "nanotecnologia", que foram escolhidos por representarem dois assuntos prioritários para o Brasil, foram realizadas pesquisas utilizando as respectivas palavras-chave no sistema de busca da própria Plataforma Lattes para obtenção do número de pesquisadores nos referidos assuntos. Em seguida, foram realizadas pesquisas no Diretório de Grupos de Pesquisa do CNPq buscando identificar os grupos de pesquisa certificados com interesse no estudo da dengue ou da nanotecnologia. Tais informações foram utilizadas para alimentar as diversas etapas computacionais que compõem o Scriptlattes. 0 passo-a-passo para reprodução desta metodologia, que pode ser empregada para avaliar as competências em qualquer assunto, pode ser acompanhado detalhadamente no trabalho original de Mena-Chalco e César Júnior (2009).

\subsection{Caso 1: Extração, tratamento e montagem das redes de colaboração dos pesquisadores em dengue no Brasil}

Na data da extração das informações que serviram de base para avaliação das redes de colaboração entre os pesquisadores em dengue cadastrados na Plataforma Lattes, foi possível identificar 15.465 pesquisadores que possuíam a palavra-chave "dengue" em algum ponto de seus currículos, embora apenas 27\% desse total (4.164 Pesquisadores, tanto brasileiros quanto estrangeiros), possuíam o título de Doutor. Destes, 589 (14\% do total de Doutores) possuíam Bolsa de Produtividade em Pesquisa, 568 (13\%) possuíam a Bolsa e também estavam inseridos em quaisquer Grupos de Pesquisa do CNPq, e 1.185 (28\%) não faziam parte de nenhum Grupo de Pesquisa. Levando-se em consideração apenas os 4.077 Doutores brasileiros, 3.214 (79\%) estavam inseridos em algum Grupo de Pesquisa do CNPq, independente da linha de pesquisa desse grupo.

Independente dos resultados iniciais fornecidos no parágrafo anterior, para que um pesquisador fosse considerado como pertencente ao core competencies em dengue, o mesmo deveria preencher dois importantes critérios 
de inclusão: possuir o descritor "dengue" em algum ponto do currículo Lattes e também pertencer a algum Grupo de Pesquisa registrado no CNPq e que possuísse a palavra "dengue" como um de seus descritores. Após a aplicação desses critérios, apenas 424 Pesquisadores (cerca de 3\% do total de pesquisadores que originalmente possuíam a palavra-chave "dengue" em seus currículos) foram selecionados. Em uma segunda etapa de seleção, pesquisadores que possuíam o descritor "dengue" no currículo em alguma publicação em parceria com os pesquisadores do core competencies (971 pesquisadores), mesmo que não pertencessem a algum grupo de pesquisa em dengue, foram considerados os "colaboradores do core competencies", e constituíram o core competencies 1 . Por fim, aqueles pesquisadores que também possuíam o descritor "dengue" no currículo, contanto que em alguma produção em parceria com os "pesquisadores do core competencies 1" (735 pesquisadores), constituíram o core competencies 2 .

\subsection{Caso 2: Extração, tratamento e montagem das redes de colaboração dos pesquisadores em nanotecnologia no Brasil}

$\mathrm{Na}$ data da extração das informações que serviram de base para avaliação das redes de colaboração entre os pesquisadores em nanotecnologia cadastrados na Plataforma Lattes, em uma busca avançada foi possível identificar 1.915 pesquisadores, grupo esse originado de um tratamento anterior que utilizou como base uma lista de 12.237 currículos, proveniente de uma procura na plataforma Lattes utilizando-se como únicos critérios o fato que os pesquisadores deveriam ser "doutores brasileiros e estrangeiros" e possuir a palavra-chave "nanotecnologia" registrada em qualquer ponto de seus currículos Lattes.

Após a etapa anterior, a lista contendo os 1.915 ID Lattes do core competencies em nanotecnologia alimentou o programa Scriplattes, permitindo a obtenção de uma lista contendo 4.288 colaboradores de nível 1, denominados core competencies 1 . Assim como no caso da dengue, o critério utilizado para seleção e extração dos ID Lattes desses pesquisadores baseou-se na existência da palavrachave "nanotecnologia" em seus currículos e também no fato de que tais 
pesquisadores deveriam ter alguma produção científica em colaboração com os 1.915 pesquisadores do core competencies. Nesse caso, foram consideradas apenas as produções científicas de maior relevância acadêmica e pontuadas a seguir: "artigo completo publicado em periódico", "artigo aceito para publicação" e "trabalho completo publicado em anais de eventos".

\subsection{Caso 3: Extração, tratamento e montagem das redes de colaboração entre os professores de um Programa de Pós-graduação Stricto Sensu em Administração}

Dando continuidade ao proposto neste trabalho, foram montadas manualmente treze listas contendo os nomes e os ID Lattes de todos os professores do Programa de Pós-Graduação Stricto Sensu em Administração de uma universidade particular sediada na cidade de São Paulo - SP, que é composto por um Programa de Mestrado e Doutorado acadêmicos e mais quatro Programas de Mestrado Profissionalizante. Além de uma visão geral da estrutura do curso, pretendeu-se nesta experimentação permitir a visualização da rede de colaboração interna existente entre os professores de cada Programa.

\subsection{Funcionamento da ferramenta}

Após a alimentação do Scriptlattes tanto com as listas manuais para a avaliação das redes de colaboração existentes entre os professores do Programa de Stricto Sensu citado, quanto com as listas geradas automaticamente para avaliação das redes de colaboração existentes entre os pesquisadores em nanotecnologia, e entre os pesquisadores em dengue, o funcionamento do sistema dividiu-se em seis módulos sequenciais, descritos a seguir.

0 primeiro módulo de funcionamento realizou o download dos currículos no formato html diretamente da plataforma Lattes, dedicando especial atenção à extração das informações relacionadas à publicação de artigos em periódicos. A segunda etapa do processamento buscou na Plataforma Lattes as informações relacionadas ao endereço profissional, à lista de produções e à lista de supervisões em andamento e concluídas (limitadas ao intervalo de tempo 
fornecido), além da fotografia do pesquisador listado. Em seguida, ocorreu a etapa de tratamento das redundâncias, onde o programa detectou e eliminou as produções duplicadas após o pré-processamento dos currículos. Na quarta etapa a ferramenta Scriptlattes criou uma representação gráfica para demonstrar a rede de colaboração entre os membros listados de um grupo, baseando-se em suas produções científicas mais relevantes, e que se constituiu no foco central da realização deste trabalho. Na penúltima fase do processamento gerou-se um mapa de geolocalização mundial dos pesquisadores listados, com base no endereço informado por eles à plataforma. Por fim, foram gerados todos os relatórios em formato html relacionados aos tratamentos descritos (MENA-CHALCO; JUNIOR; MARCONDES, 2009).

\section{RESULTADOS E DISCUSSÃO}

A presente sessão limitou-se em demonstrar, de acordo com a proposta inicial do trabalho, apenas as redes multidisciplinares de colaboração estabelecidas entre os professores de um Programa de Pós-Graduação Stricto Sensu em Administração, entre os pesquisadores em dengue cadastrados na Plataforma Lattes, e entre os pesquisadores em nanotecnologia cujos currículos também se encontravam disponíveis na Plataforma na data das extrações. A ferramenta Scriptlattes fornece inúmeras possibilidades de visualização gráfica dessas redes, originadas de ferramentas como Treecloud ${ }^{\circledR}$, Gephi $^{\odot}$, Cowo $^{\odot}$ e VOSviewer, já acopladas ao Scriptlattes. Além das redes de colaboração entre os autores, ainda se permite visualizar graficamente as relações entre os títulos das variadas produções científicas cadastradas nos currículos de cada pesquisador, como os artigos, trabalhos apresentados em eventos, dissertações, teses, produções artísticas, técnicas, tecnológicas, dentre outros. Nesta experimentação, buscou-se demonstrar as inúmeras possibilidades de análise gráfica aqui descritas com base em alguns exemplos de tratamento dos casos elencados para tratamento, fornecidos pela ferramenta Scriptlattes. As análises podem ser vistas em sua totalidade bastando para tal acessar os endereços eletrônicos fornecidos ao final do trabalho. 
Vale aqui ressaltar que resultados fornecidos pelo Scriptlattes não se limitam apenas às redes multidisciplinares. Também são disponibilizados mapas de geolocalização dos pesquisadores listados, gráficos de evolução da produção científica e internacionalização da pesquisa, além das listas completas de cada tipo de produção. Dessa forma, com base em informações relacionadas às orientações e projetos de pesquisa vigentes é possível, por exemplo, realizar uma prospecção dos futuros resultados das pesquisas em andamento. Se tomarse como base os produtos técnicos e tecnológicos, é possível avaliar as contribuições práticas que os resultados das pesquisas científicas têm dado à população. Algumas dessas informações, relativas aos casos aqui descritos, já estão disponíveis na literatura (QUONIAM; FERRAZ, 2014), e também podem ser acessadas nos endereços eletrônicos de acesso fornecidos ao final da sessão de Referências.

\subsection{Caso 1: Rede de multidisciplinar de colaboração entre os Professores de um Programa de Pós-graduação Stricto Sensu em Administração}

No caso do Programa de Pós-graduação avaliado, optou-se pelos gráficos gerados pelo próprio Scriptlattes, além daqueles gerados pelos softwares Gephi ${ }^{\circledR}$ e Treecloud ${ }^{\odot}$, para apresentar graficamente as redes multidisciplinares fornecidas após o tratamento dos currículos.

A Figura 1 permite visualizar parcialmente um dos modelos de representação gráfica das parcerias já realizadas entre alguns dos professores do Programa de Pós-Graduação Stricto Sensu avaliado, fornecidas pela ferramenta Scriptlattes. No interior dos quadros estão os nomes desses Professores. Cada linha unindo os quadros representa uma parceria entre os Pesquisadores neles listados. Cabe ressaltar que as parcerias apresentadas são limitadas ao conjunto de ID Lattes contemplados nas listas de alimentação do Scriptlattes e não levam em consideração possíveis parcerias realizadas com colaboradores externos ao Programa avaliado.

As possibilidades de visualização das redes no caso da avaliação de um Programa de Pós-Graduação são inúmeras. É possível visualizar a rede de colaborações, por exemplo, entre os professores de todo o Programa, entre os 
professores pertencentes a um dos cursos que compõem o Programa, ou mesmo entre os pesquisadores de uma linha de pesquisa que compõe o curso.

Figura 1. Gráfico de colaborações entre os Professores de um dos cursos que compõem o Programa de Pós-graduação avaliado, elaborado pelo software Scriptlattes.

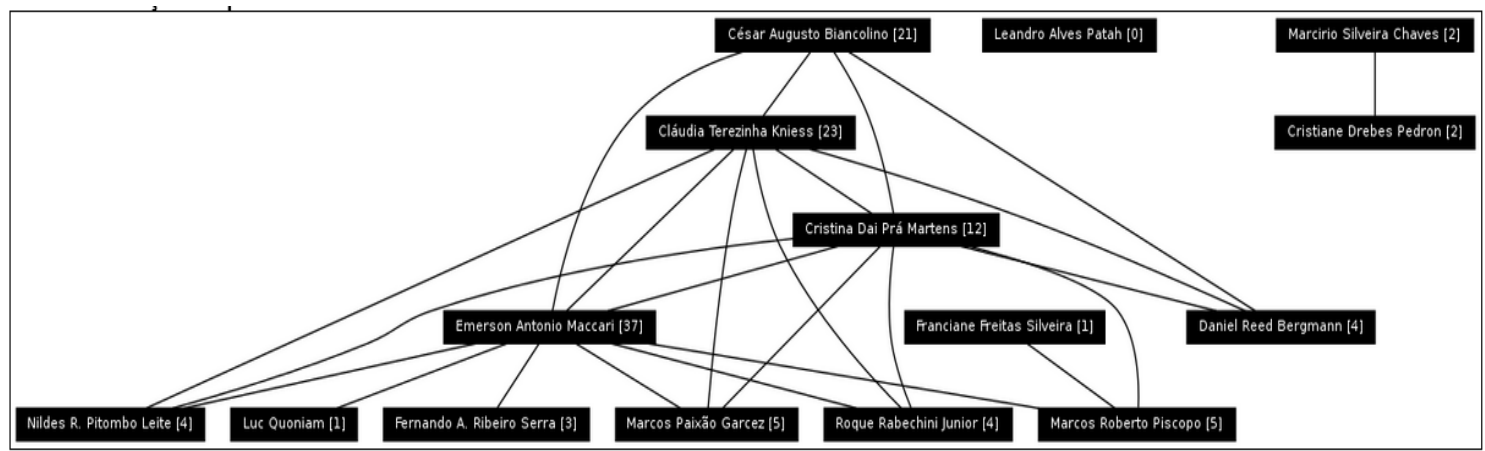

A análise da mesma rede de colaborações com o software Gephi ${ }^{\circledR}$ (Figura 2A), disponibilizada automaticamente pela ferramenta Scriptlattes, caracterizase por realizar a montagem de uma rede tridimensional contendo todos os pesquisadores listados em um dos arquivos de alimentação da ferramenta, que foi utilizado como exemplo nesta experimentação. Nessa representação, cada esfera traz o nome de um pesquisador da lista. 0 tamanho de cada esfera depende do número de relações que o pesquisador possui com os demais pesquisadores listados.

Ao clicar sobre a esfera representativa de um pesquisador qualquer (seta indicativa na Figura 2B), é possível notar que serão colocadas em destaque apenas as redes de colaboração existentes entre o pesquisador escolhido e os outros pesquisadores presentes na mesma lista que alimentou a ferramenta, o que é válido para qualquer uma das esferas presentes na representação gráfica, independente do número de parcerias realizadas por aquele pesquisador. 
Figura 2A. Análise das colaborações entre os componentes do Programa de PósGraduação avaliado (visão total), elaborada pelo software Scriptlattes utilizando o software Gephi ${ }^{\odot}$.

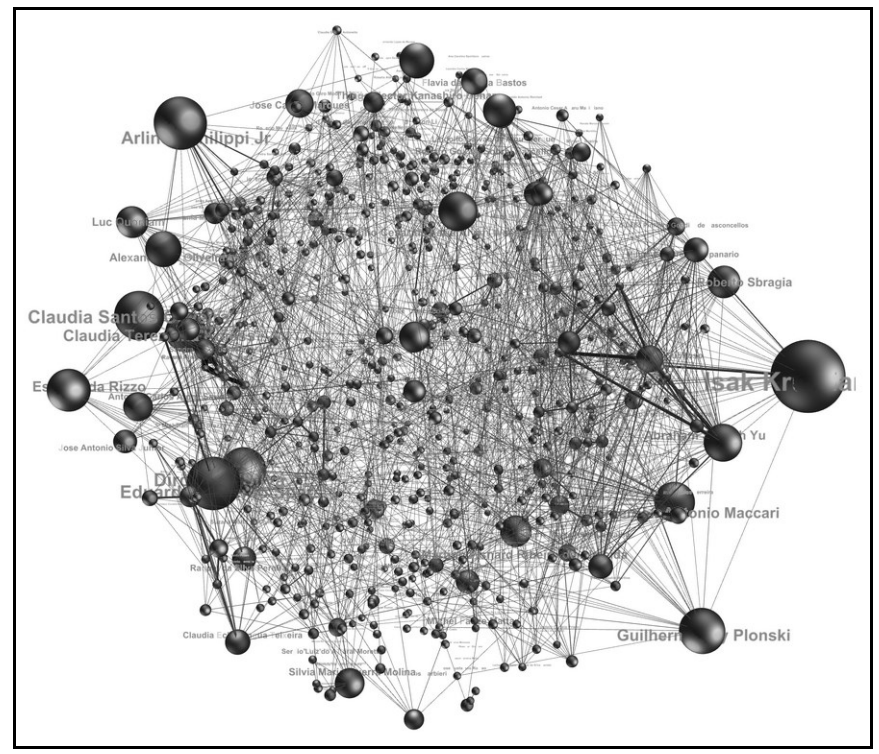

Figura 2B. Análise das colaborações de apenas um pesquisador pertencente ao Programa de Pós-graduação avaliado, elaborada pelo software Scriptlattes utilizando o software Gephi ${ }^{\odot}$.

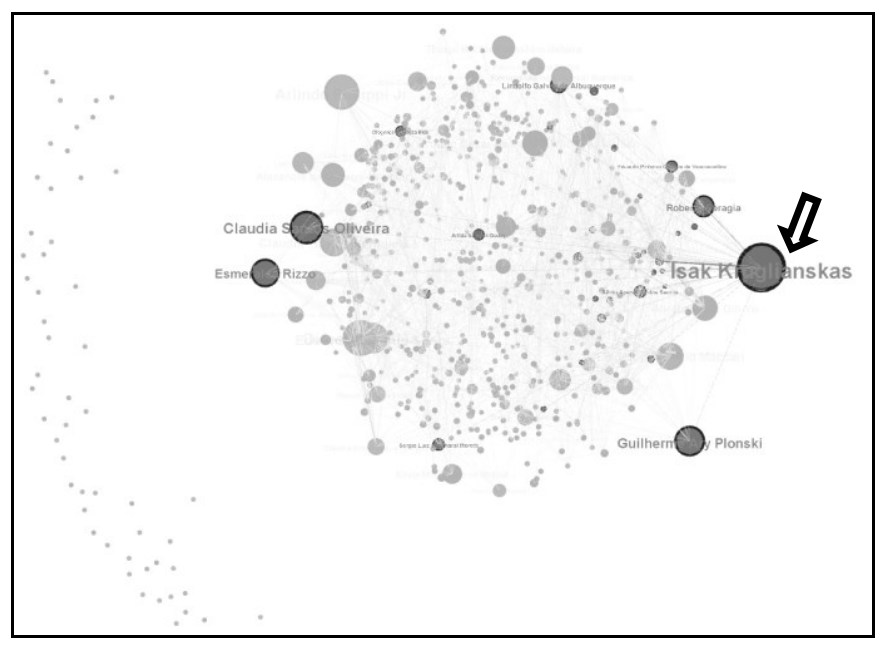

Além da análise das redes de colaboração existentes entre os pesquisadores em um determinado assunto, a ferramenta Scriptlattes também é capaz de fornecer ao final do tratamento uma análise gráfica em forma de rede contendo, por exemplo, os títulos dos artigos completos publicados em periódicos, gerada com o software Treecloud ${ }^{\circledR}$, e disponibilizada automaticamente pela ferramenta (Figuras 3A e 3B). A análise gráfica apresentada distribui de maneira centrífuga os principais assuntos 
disponibilizados nos títulos dos artigos completos publicados em periódicos, modalidade de produção eleita para esta experimentação.

Figura 3A. Análise dos títulos dos artigos completos publicados em periódicos pelos professores do Programa de Pós-Graduação avaliado (visão total), elaborado pelo software Scriptlattes utilizando o software Treecloud ${ }^{\odot}$.

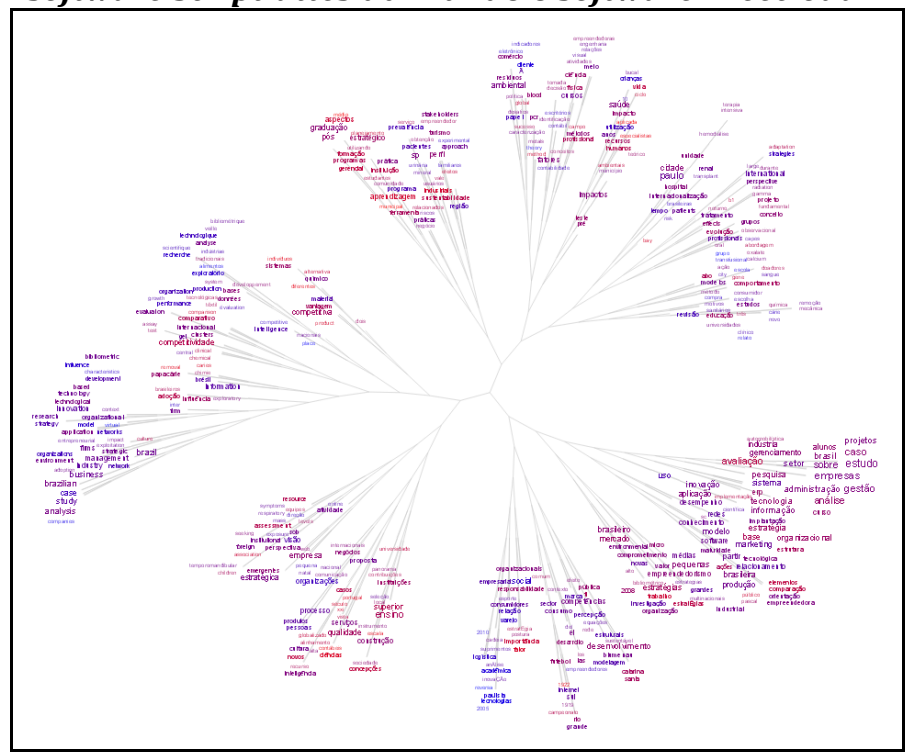

Figura 3B. Análise dos títulos dos artigos completos publicados em periódicos pelos professores do Programa de Pós-Graduação avaliado (visão parcial e ampliada), elaborado pelo software Scriptlattes utilizando o software Treecloud $^{\odot}$.

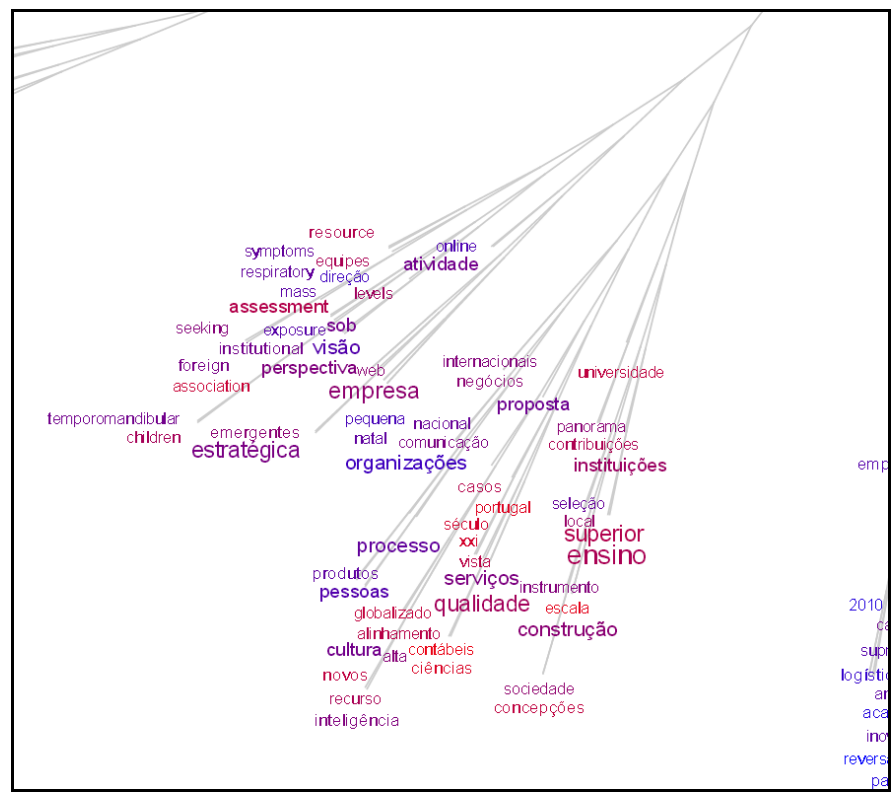




\subsection{Caso 2: Rede multidisciplinar de colaboração entre os pesquisadores em nanotecnologia que exercem atividades ligadas a instituições brasileiras}

$\mathrm{Na}$ análise das redes multidisciplinares existentes entre os pesquisadores em nanotecnologia, optou-se pelos gráficos gerados pelo próprio Scriptlattes, por meio da utilização dos softwares Cowo ${ }^{\circledR}$ e VOSviewer ${ }^{\circledR}$.

As análises disponíveis nas Figuras 4A (visão total) e 4B (visão parcial e ampliada) demonstram a representação gráfica criada com base nos títulos dos projetos em nanotecnologia registrados na Plataforma Lattes pelos pesquisadores que atuam em instituições brasileiras. É possível verificar que os assuntos são agrupados em diferentes cores de acordo com suas similaridades, e que alguns desses assuntos são compartilhados por diferentes categorias, critério utilizado para posicionar tais assuntos dentro de cada área. Nos gráficos, o tamanho da letra utilizada para nomear os assuntos é proporcional ao número de projetos existentes para cada assunto.

Figura 4A. Análise dos títulos dos projetos em nanotecnologia registrados na Plataforma Lattes (visão total), elaborada pelo software Scriptlattes com a utilização dos softwares Cowo $^{\circledR}$ e VOSviewer $^{\oplus}$ (cluster density view).

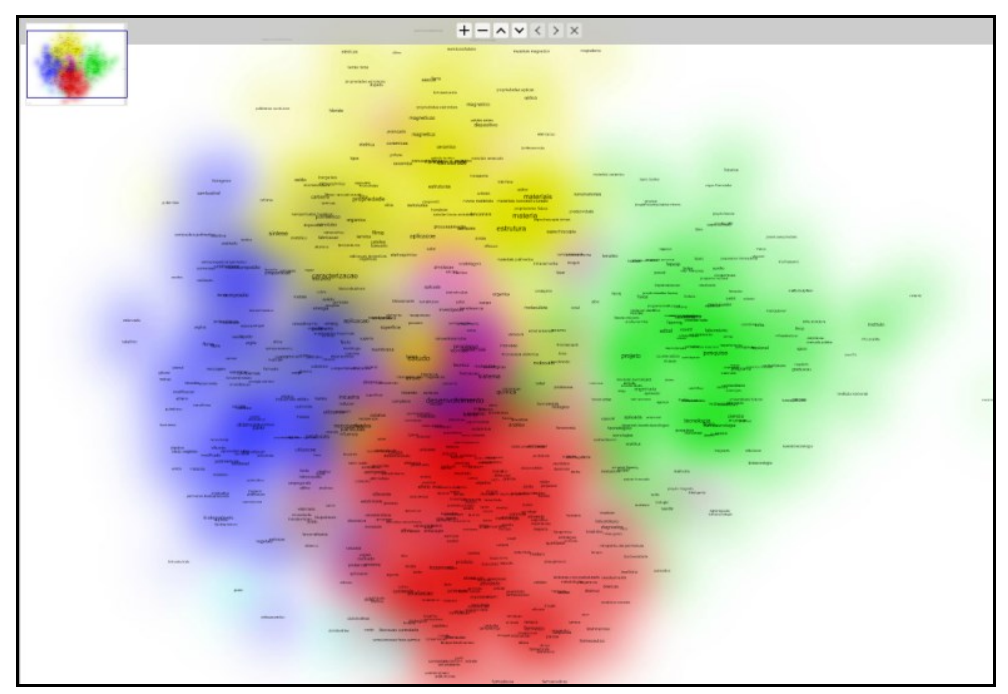


Figura 4B. Análise dos títulos dos projetos em nanotecnologia registrados na Plataforma Lattes (visão parcial e ampliada), elaborada pelo software Scriptlattes com a utilização dos softwares Cowo $^{\oplus}$ e VOSviewer $^{\oplus}$ (cluster density view).

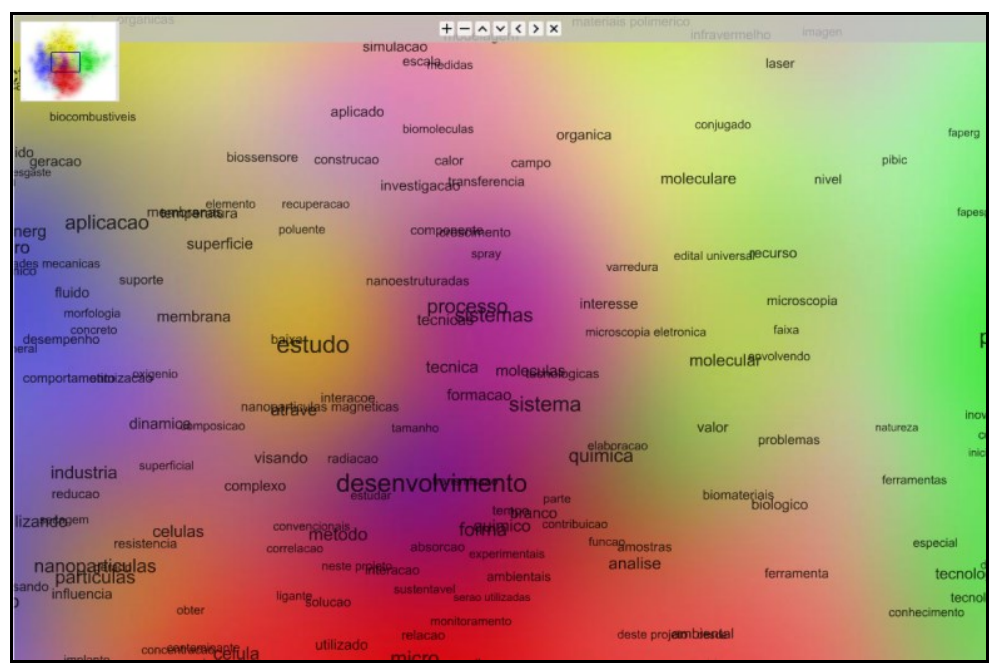

As representações gráficas disponibilizadas nas Figuras 5A (visão total) e 5B (visão parcial e ampliada) correspondem a uma diferente maneira de apresentação dos títulos das produções científicas que alimentam a Plataforma Lattes, dessa vez levando-se em consideração os produtos tecnológicos sobre o tema nanotecnologia. As esferas representam cada um dos assuntos contemplados pelos respectivos produtos. 0 tamanho das esferas é diretamente proporcional à quantidade de produtos registrados sobre cada assunto.

Figura 5A. Análise dos títulos dos produtos tecnológicos em nanotecnologia registrados na Plataforma Lattes (visão total), elaborada pelo software Scriptlattes com a utilização dos ${\text { softwares } \text { Cowo }^{\odot} \text { e VOSviewer }}^{\odot}$ (label view).

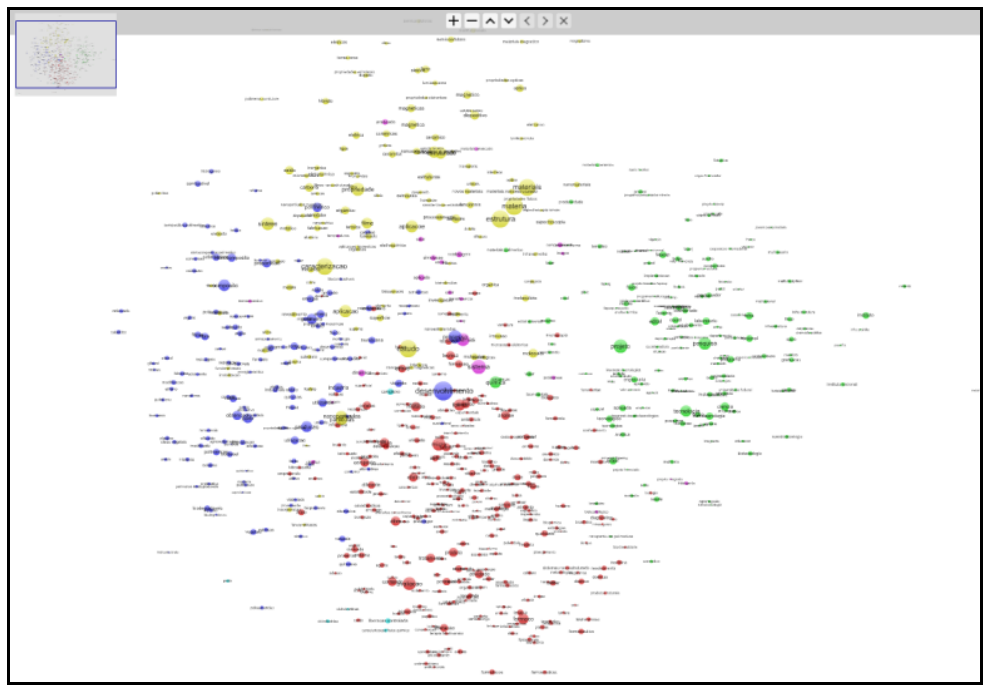


Figura 5B. Análise dos títulos dos produtos tecnológicos em nanotecnologia registrados na Plataforma Lattes (visão parcial e ampliada), elaborada pelo software Scriptlattes com a utilização dos softwares Cowo ${ }^{\circledR}$ e VOSviewer ${ }^{\circledR}$ (label view).

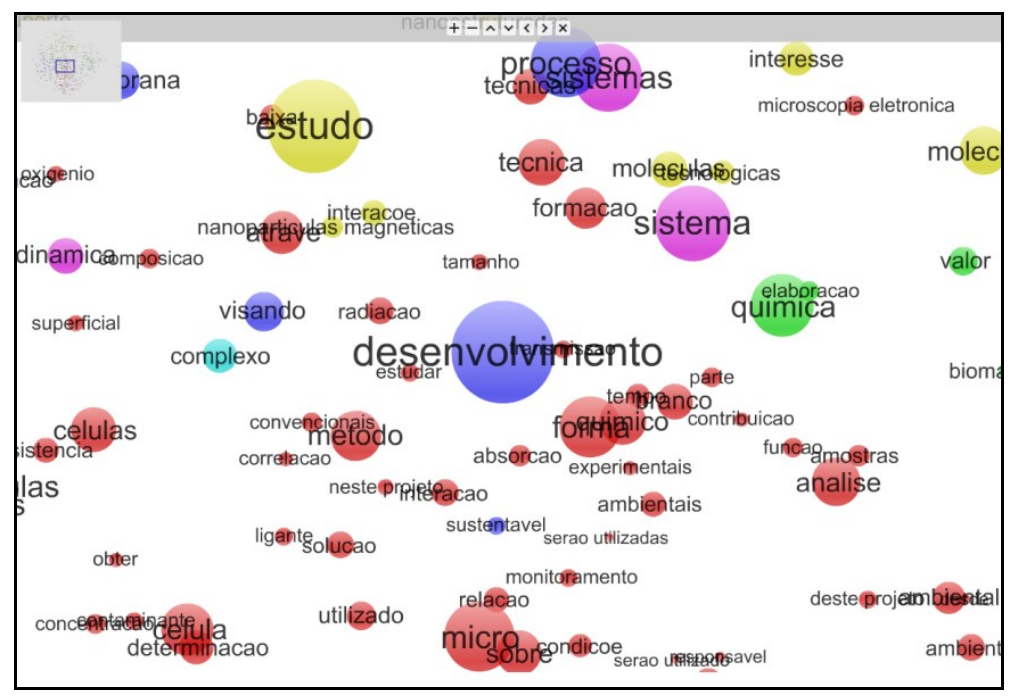

As análises das relações estabelecidas pelos pesquisadores em um determinado assunto são essenciais para o estabelecimento de estratégias que visem alavancar o conhecimento científico pertinente ao tema pesquisado ${ }^{\text {i. Nas }}$ Figuras 6A, 6B e 6C é possível observar, em ampliações de tamanho respectivamente crescente, a rede tridimensional contendo os nomes dos pesquisadores pertencentes ao core competencies em nanotecnologia no país, que são representados por esferas coloridas, disponibilizadas pelo Scriptlattes com a com a utilização do software Gephi ii. À partir da Figura 6B podem ser vistas esferas de diferentes tamanhos, que são diretamente proporcionais ao número de colaborações realizadas pelos pesquisadores por ela representados, que são indicadas pelas linhas contínuas que interligam as esferas. Dessa forma, as pequenas esferas representam pesquisadores com reduzido (ou nenhum) número de colaborações. A Figura 6C demonstra que, ao clicar em uma esfera escolhida aleatoriamente, é possível destacar a rede de colaborações do pesquisador representado pela esfera escolhida. 
Figura 6A. Rede de colaborações total levando-se em consideração os pesquisadores em nanotecnologia ligados à instituições brasileiras, elaborada pelo software Scriptlattes utilizando o software Gephi ${ }^{\circ}$.

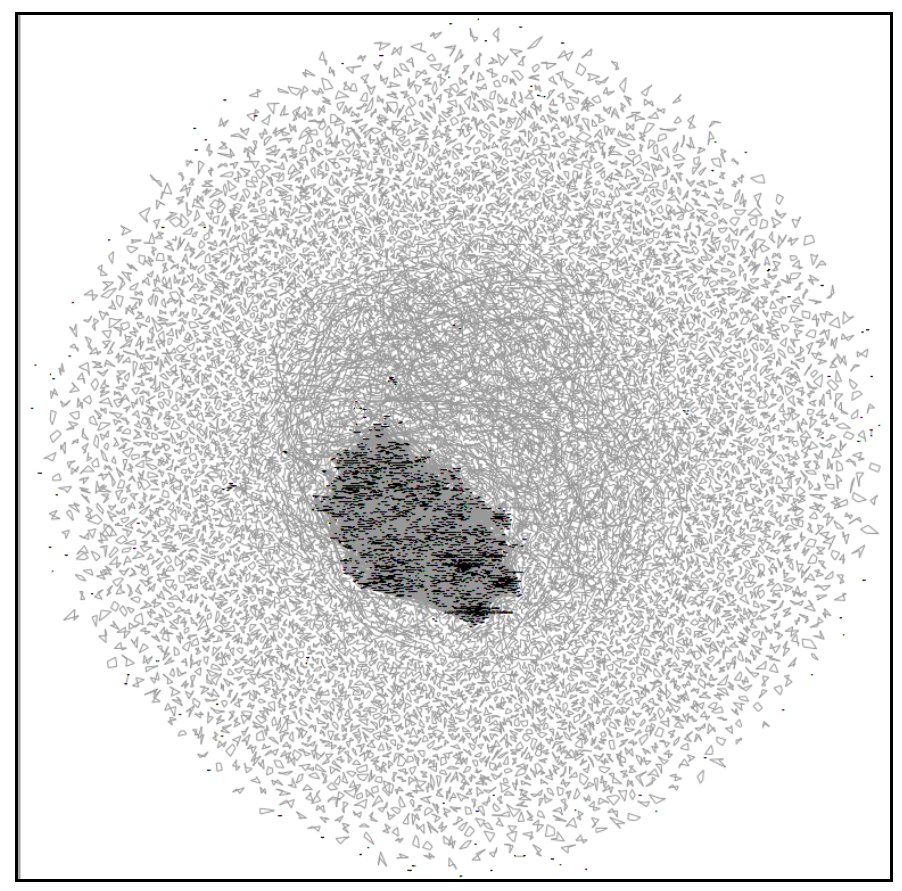

Figura 6B. Rede de colaborações reduzida levando-se em consideração os Pesquisadores em nanotecnologia ligados à instituições brasileiras, elaborada pelo software Scriptlattes utilizando o software Gephi ${ }^{\circ}$.

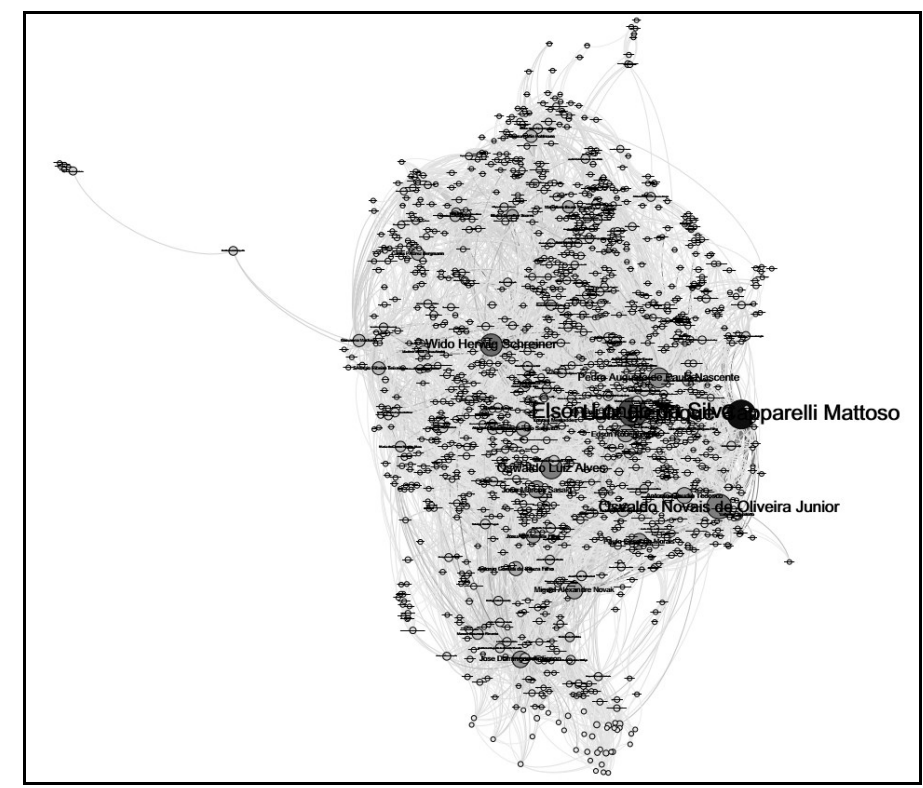


Figura 6C. Rede de colaborações reduzida (em tamanho ampliado) levando-se em consideração os Pesquisadores em nanotecnologia ligados à instituições brasileiras, destacando a rede de colaborações de um Pesquisador escolhido aleatoriamente, elaborada pelo software Scriptlattes utilizando o software Gephi ${ }^{\odot}$.

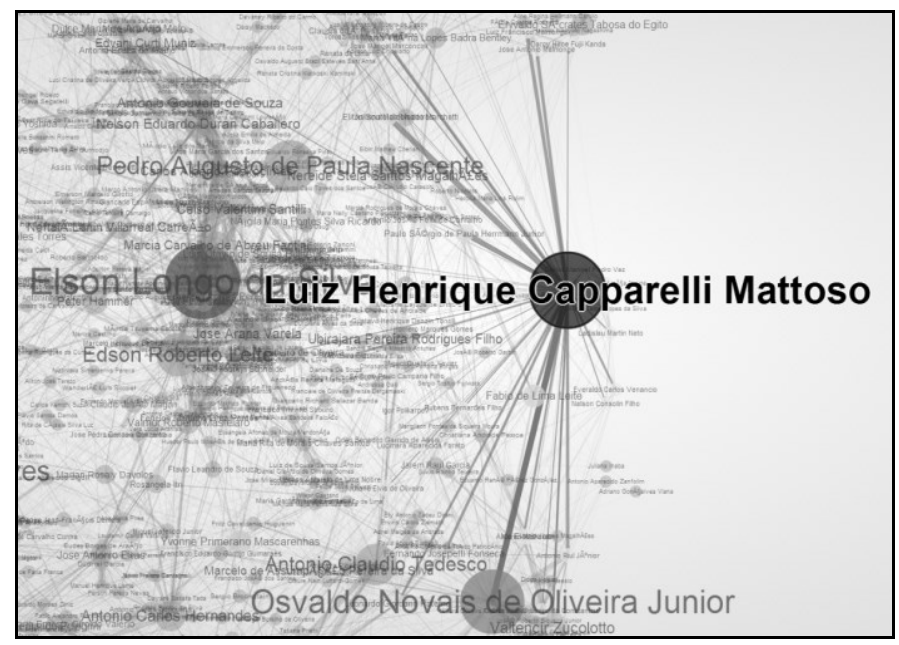

\subsection{Caso 3: Rede multidisciplinar de colaboração entre os pesquisadores} em dengue que exercem atividades ligadas a instituições brasileiras

Para a análise das redes multidisciplinares existentes entre os pesquisadores em dengue, optou-se pelos gráficos gerados pelo próprio Scriptlattes, por meio da utilização dos softwares Flashxml.net e Treemap ${ }^{\circledR}$.

O software Flashxml.net foi utilizado nesta experimentação para demonstrar a evolução numérica dos grupos de pesquisa em dengue no decorrer dos anos. Nessa representação, as esferas na cor vermelha representam os estados brasileiros e as esferas na cor azul representam os assuntos pesquisados pelos respectivos grupos. 0 tamanho das esferas é diretamente proporcional ao número de grupos de pesquisa levando-se em consideração o total de grupos por estado e por assunto de interesse.

A Figura 6A permite verificar que, no ano de 1966, existiam apenas grupos de pesquisa em dengue especificamente voltados ao estudo dos fatores genéticos associados à doença, e que estes grupos estavam vinculados à instituições localizadas no estado de São Paulo. Já na Figura 6B, que representa o ano de 1996, é possível verificar que os grupos de pesquisa em dengue se dedicavam ao estudo de apenas oito assuntos, com destaque especial para a microbiologia, que possuía o maior número de grupos. Na figura ainda é 
possível observar que esses grupos estavam distribuídos em sete estados da Federação, sendo o estado do Rio de Janeiro aquele com o maior número de grupos à época. Por fim, a Figura 6C demonstra que, já no ano de 2012, os grupos de pesquisa em dengue já desenvolviam pesquisas em mais de vinte assuntos diferentes, e que esses grupos estavam distribuídos na maioria dos estados brasileiros, sendo Rio de Janeiro, Minas Gerais e São Paulo aqueles que, respectivamente, possuíam o maior número de grupos de pesquisa em dengue no país. A maioria desses grupos desenvolvia à época trabalhos na área de microbiologia, semelhante ao que era observado já na década de 1990, seguida pelas áreas de saúde coletiva, bioquímica, medicina, parasitologia e imunologia, dentre outros.

Figura 6A. Representação gráfica da dinâmica de criação de grupos de pesquisa em dengue, distribuídos pelos estados brasileiros no ano de 1966, fornecida pelo software Scriptlattes utilizando o software Flashxml.net.

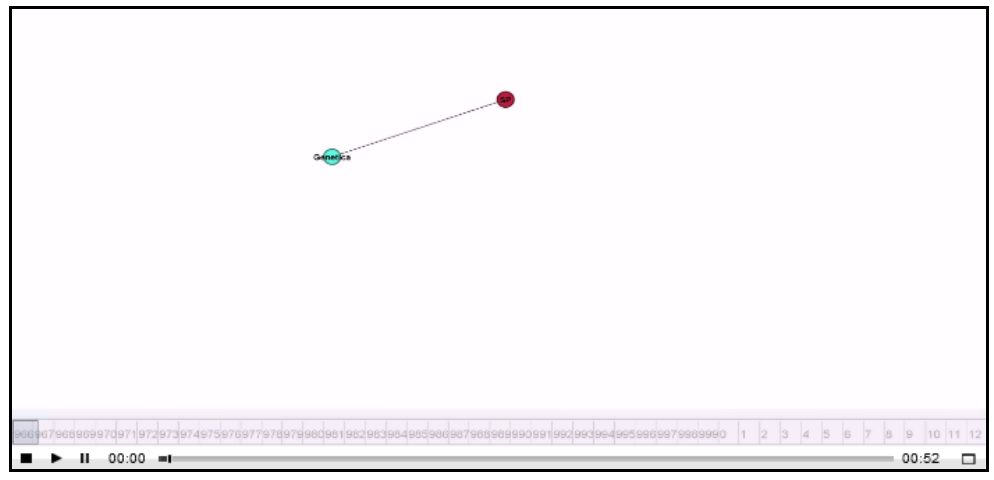

Figura 6B. Representação gráfica da dinâmica de criação de grupos de pesquisa em dengue, distribuídos pelos estados brasileiros no ano de 1992, fornecida pelo software Scriptlattes utilizando o software Flashxml.net.

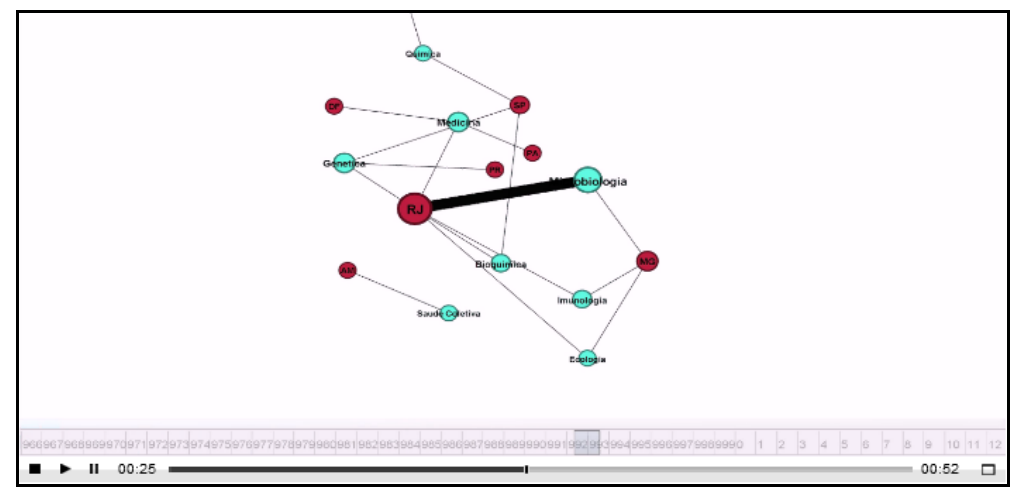




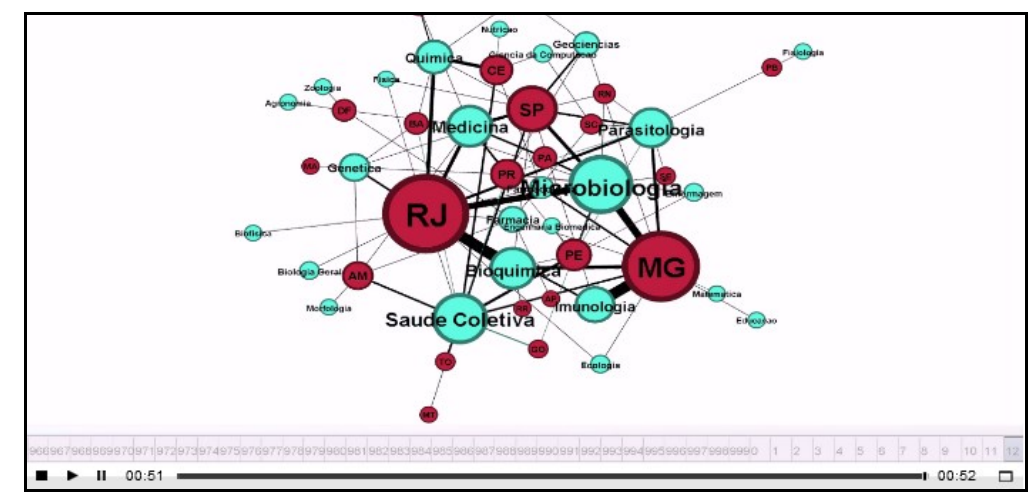

As Figuras 7A e 7B trazem as representações gráficas disponibilizadas pelo Scriptlattes com o uso do software Treemap ${ }^{\circledR}$. Na análise, é possível verificar que os grupos de pesquisa são agrupados por assunto geral, e dentro de cada estado da Federação. A área ocupada pelo quadro representativo do assunto geral dentro de cada estado, e a área ocupada por cada estado dentro do território brasileiro, são diretamente proporcionais ao número de grupos de pesquisa existentes em cada uma das subdivisões citadas. Na Figura 7A é possível verificar que o estado do Rio de Janeiro ocupa a maior área no mapa, já que possui grupos de pesquisa registrados em treze diferentes assuntos gerais, sendo a bioquímica o assunto com o maior número de grupos de pesquisa certificados por suas instituições, seguido da microbiologia, medicina e parasitologia.

A Figura 7B demonstra que, ao clicar sobre a área representativa do estado de São Paulo, é possível obter uma ampliação do quadro de assuntos, que foram divididos nos temas que compõem cada um dos assuntos gerais destacados pelo sistema na Figura 7A. Dentro dos temas de interesse dos principais grupos de pesquisa certificados no estado, a medicina é a grande área em destaque, com três subgrupos de assuntos de interesse em pesquisa em dengue, que são hemoterapia e hematologia, métodos quantitativos e epidemiologia hospitalar. Após a medicina, vêm os assuntos gerais microbiologia, parasitologia e saúde coletiva, cada um com duas subdivisões de assuntos de interesse, seguidos da física, genética, geociências e química, que possuem apenas um assunto específico contendo grupos certificados. 
Figura 7A. Rede de grupos de pesquisa no Brasil distribuídos por Estados, com o software Treemap ${ }^{\odot}$.

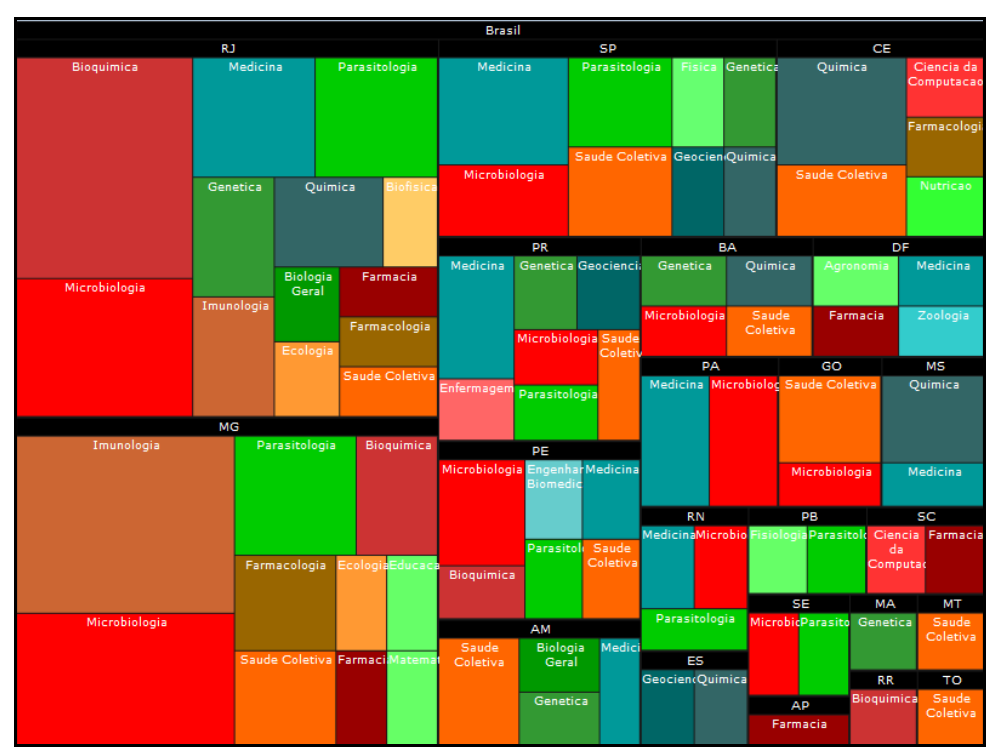

Figura 7B. Rede de grupos de pesquisa do Estado do Rio Janeiro distribuídos por assunto, com o software Treemap ${ }^{\odot}$.

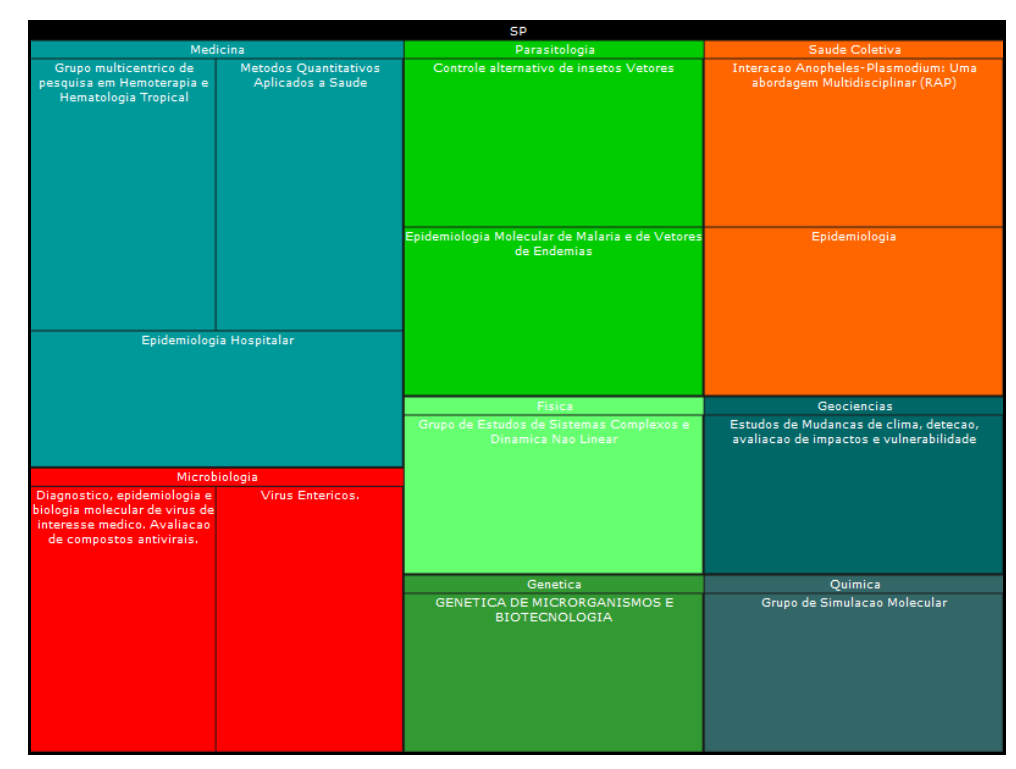

\section{CONCLUSÕES}

Na presente experimentação a ferramenta computacional Scriptlattes foi utilizada para demonstrar as redes multidisciplinares de pesquisa relacionadas aos assuntos nanotecnologia e dengue, ambos prioritários para o Brasil, assim 
como para demonstrar as redes existentes entre os professores pertencentes a um Programa de Pós-Graduação Stricto Sensu em Administração.

Os resultados desta pesquisa confirmaram a eficácia do Scriptlattes com relação às análises de informação propostas, bem como à disponibilização das referidas em páginas de fácil acesso na internet, que podem ser visualizadas por qualquer interessado e em qualquer lugar do mundo, contribuindo assim para a transparência da ciência. A disponibilização dos resultados, além facilitar a visualização de maneira organizada de uma série de informações anteriormente fragmentadas e disponíveis apenas nos currículos individuais dos pesquisadores cadastrados na Plataforma Lattes, contribui na divulgação ao grande público dos resultados das pesquisas realizadas entre as redes de colaboração em pesquisa, que na sua maioria são financiadas pelos órgãos públicos e, por isso, devem ser divulgados de maneira transparente para toda a comunidade.

De modo geral, a ferramenta Scriptlattes constitui-se em uma forma simples de se obter um levantamento das redes multidisciplinares existentes não só entre os pesquisadores de determinadas áreas como nanotecnologia $\mathrm{e}$ dengue, mas também sobre os principais grupos de pesquisa em determinado assunto, analisando o andamento de suas produções bem como informações relevantes relacionadas às atividades por eles desempenhadas, além de sua evolução ao longo do tempo, tanto por estado quanto por assunto de interesse.

Com relação à análise das redes multidisciplinares estabelecidas entre os professores do Programa de Pós-Graduação avaliado, acredita-se que tais informações podem ser importantes especialmente para os gestores dos Programas de Stricto Sensu, que poderão acompanhar as parcerias entre os professores e estabelecer estratégias para alavancar a produção científica de seus pares, visto que as redes de colaboração são eficientes para tal. De certa forma, o aumento da produção científica, comum quando se estabelecem parcerias em pesquisa, é fator de maior peso na definição da nota final que os cursos de Pós-Graduação receberão ao final da avaliação trienal, que é feita pela CAPES. 
No âmbito da Gestão em Saúde, a apresentação dos dados relacionados à dengue possibilita que os órgãos públicos regulamentadores acompanhem a evolução temporal dos grupos de pesquisa, das redes de colaboração entre os pesquisadores, bem como a evolução da sua produção científica, permitindo a criação ou reformulação das ações e programas de saúde direcionados especialmente para diagnóstico, tratamento e prevenção de importantes condições clínicas como a dengue, assim como a avaliação das atuais políticas de concessão de fomento pública para pesquisa.

Com relação à nanotecnologia, outro assunto prioritário para o Brasil, mostra-se de extrema valia conhecer e entender as redes multidisciplinares estabelecidas entre os pesquisadores, assim como a evolução dos grupos de pesquisa ao longo do tempo e os assuntos de interesse dos referidos grupos, especialmente com o propósito de avaliar se os mesmos suprem as expectativas relacionadas às pesquisas no tema. A indústria brasileira compete diretamente com os produtos importados de elevada tecnologia. Dessa forma, o Brasil somente se tornará um país competitivo em nanotecnologia se aumentar sua capacidade de gerar produtos e processos inovadores, possam ser comparados aos provenientes da indústria internacional e, para tal, necessita identificar, acompanhar e promover as pesquisas e, consequentemente, o avanço na pesquisa em nanotecnologia.

\section{REFERÊNCIAS}

ALVES, A. D.; YANASSE, H. H.; SOMA, N. Y. LattesMiner: uma linguagem de domínio específico para extração automática de informações da Plataforma Lattes. In: XII WORKSHOP DE COMPUTAÇÃO APLICADA. São José dos Campos: 6 nov. 2012. Disponível em: <http://mtcm18.sid.inpe.br/col/sid.inpe.br/mtcm18/2013/01.15.16.10/doc/worcap2012_submission_61\%20\%20Alexandre\%20D.\%20Alves.pdf>. Acesso em: 5 nov. 2013

BALANCIERI, R. et al. A análise de redes de colaboração científica sob as novas tecnologias de informação e comunicação: um estudo na Plataforma Lattes. Ciência da Informação, v. 34, n. 1, p. 64-77, 2005. 
CASTELLS, M.; CARDOSO, G. The network society: From knowledge to policy. Center for Transatlantic Relations, Paul H. Nitze School of Advanced International Studies, Johns Hopkins University, 2006.

CAVALCANTE, G. V. Ciência das redes: aspectos epistemológicos. 2011.

FERREIRA, H. et al. Estudo epidemiológico localizado da frequência e fatores de risco para enteroparasitoses e sua correlação com o estado nutricional de crianças em idade pré-escolar. Publicatio UEPG: Ciências Biológicas e da Saúde, v. 12, n. 4, 2009.

GUEDES, C. A. Conselho Nacional de Desenvolvimento Científico e Tecnológico (CNPq). Currículo Lattes: Perguntas e Respostas. Disponível em: <http://www.pucrs.campus2.br/manuais/dicas_lattes.pdf>. Acesso em: 6 nov. 2013.

HOTEZ, P. A new voice for the poor. PLoS neglected tropical diseases, v. 1, n. 1, p. e77, 2007.

KOSTOFF, R. N.; KOYTCHEFF, R. G.; LAU, C. G. Global nanotechnology research literature overview. Technological Forecasting and Social Change, v. 74, n. 9, p. 1733-1747, 2007.

LEITE, P.; MUGNAINI, R.; LETA, J. A new indicator for international visibility: exploring Brazilian scientific community. Scientometrics, v. 88, n. 1, p. 311$319,2011$.

MACCARI, E. A. Contribuições à gestão dos programas de pós-graduação stricto sensu em administração no Brasil com base nos sistemas de avaliação norte americano e brasileiro. Doutorado - São Paulo: Universidade de São Paulo. Faculdade de Economia, Administração e Contabilidade., 2008.

MACHADO, R. DAS N. Scientometric analysis of bibliometric studies published in brazilian library and information science journals (1990-2005). Perspectivas em Ciência da Informação, v. 12, n. 3, p. 2-20, 2007.

MATHEUS, R. F.; PARREIRAS, F. S.; PARREIRAS, T. A. S. Análise de redes sociais como metodologia de apoio para a discussão da interdisciplinaridade na ciência da informação. Ciência da Informação, v. 35, n. 1, p. 72-93, 2006.

MATHEUS, R. F.; SILVA, A. B. DE O. Análise de redes sociais como método para a Ciência da Informação. DataGramaZero - Revista de Ciência da Informação, v. 7, n. 2, 2006.

MENA-CHALCO, J. P.; JUNIOR, C.; MARCONDES, R. ScriptLattes: an open-source knowledge extraction system from the Lattes platform. Journal of the

Brazilian Computer Society, v. 15, n. 4, p. 31-39, 2009. 
MUGNAINI, R.; LEITE, P.; LETA, J. Fontes de informação para análise de internacionalização da produção científica brasileira. Ponto de Acesso, v. 5, n. 3, p. 87-102, 2012.

PRICE, D. DE S. Networks of scientific papers. Science, v. 149, n. 3683, p. 510$515,1965$.

QUONIAM, L.; FERRAZ, R. R. N. A utilização da ferramenta computacional Scriptlattes para avaliação das competências em pesquisa no Brasil. Revista PRISMA. COM, n. 21, 2014.

ROCHA, A. D. J. 0 impacto social das doenças negligenciadas no Brasil e no mundo. Trabalho de Conclusão de Curso (Medicina) - Salvador: Universidade Federal da Bahia, 2012.

WATTS, D. Small Worlds: the dynamics of networks between order and randonmness. New Jersey: Princeton University Press, 1999.

WERNECK, G. L.; HASSELMANN, M. H.; GOUVEAA, T. G. Panorama dos estudos sobre nutrição e doenças negligenciadas no Brasil. Ciênc Saúde Coletiva, v. 16, p. 39-62, 2011.

WHO | Control of Neglected Tropical Diseases, "Sustaining the drive to overcome the global impact of neglected tropical diseases". Disponível em: <http://www.who.int/neglected_diseases/en/>. Acesso em: 24 set. 2013.

WILDER-SMITH, A.; GUBLER, D. J. Geographic Expansion of Dengue: The Impact of International Travel. Medical Clinics of North America, v. 92, n. 6, p. 13771390, nov. 2008.

YAMEY, G. The world's most neglected diseases: Ignored by the pharmaceutical industry and by public-private partnerships. BMJ: British Medical Journal, v. 325, n. 7357, p. 176, 2002. 
